\title{
Hypotheses in librarianship Applying the Scientific Method
}

W hat defines research in librarianship? One potential definition is that research in librarianship is the advancement of the field through the scholarly communication of successful (and unsuccessful) services offered within the libraries. You may recognize this definition as case study research, which is popular among practicing librarians, and comprises a large portion of the scholarly librarianship literature.

But is this really research? Certainly a real research paper includes the isolation of a natural chemical product, social behavior patterns of migrating bumblebees, or the quantitative tensile test properties of a new composite material, right? Well, no. The latter examples are what our colleagues in the physical, natural, and engineering sciences may think of when they hear the word research. Librarians, generally, are thinking of something entirely different within the field of librarianship, perhaps a new service, new management structure, emerging technology, or a renovation project within the library. So, at first glance, the research performed by scientists and librarians shares little in common. But, scientists and librarians are more alike than you think, particularly when it comes to research. Let me explain.

Great scientists use the Scientific Method, the most powerful method we have to gain new knowledge. Many argue that a proper scientific method is based on multiple hypotheses and disproof. Briefly, science starts with a question or observation, then multiple hypotheses are formed, data is collected through experimentation, and the hypotheses are eliminated by disproving them experimentally one-by-one until only one hypothesis remains. The hypothesis that survives would serve as the most probable hypothesis and ultimately leads to conclusions and new knowledge. ${ }^{1-3}$ As an aside, the conditional use of Ockham's razor is often used when two competing hypotheses exist. The result of applying Ockham's razor leaves only the simplest hypothesis or explanation. ${ }^{4}$

Great librarians also use the Scientific Method. Suppose you wanted to start a new library service, perhaps initiated by several patrons over the past year asking for this service (a question or observation). After deciding on what new service to offer, the next logical step is to come up with a few potential methods, better yet-hypotheses, to deliver the service. These hypotheses are then tested by piloting (experimenting) the new service with the different delivery methods. Qualitative or ideally quantitative assessment data is collected. The assessment data collected will serve to either support or refute the hypotheses. The hypotheses

Vincent F. Scalfani is science and engineering librarian at the University of Alabama's Rodgers Library for Science and Engineering in Tuscaloosa, Alabama, email: vfscalfani@ua.edu

() 2015 Vincent F. Scalfani 
(delivery methods) that were not effective are abandoned and disproved, leaving only the most probable hypothesis; that is, the most ideal and effective method of service delivery.

At this point, conclusions can be made, new knowledge is gained, and the library services are advanced. Importantly, if only one initial hypothesis was formed, you are unlikely to find the most probable hypothesis (i.e., the most effective delivery method). ${ }^{5}$ And as a final note, hypotheses are frequently revisited, revised, and disproved. Any hypothesis that is accepted today can be easily disproved tomorrow if new information is discovered, especially in situations where there are two competing hypotheses. ${ }^{6}$ In other words, your current library services, library management, and delivery methods will need to be evaluated often.

So while the areas that research scientists and librarians study may have little in common, the process by which the study is conducted has much in common. We share the systematic approach of the Scientific Method. It is critical to realize that the systematic approach within the Scientific Method is the fastest and most efficient method we have to gain new knowledge. ${ }^{7}$ Some exceptions exist, though these are rare. ${ }^{8}$ As such, I urge all librarians to carefully study the Scientific Method and use it daily regarding all aspects of librarianship.

A professor once told me that science is not complete until it is published. The same is true for librarianship. If we want to truly advance our field through the communication of case study research, we must embrace the Scientific Method, clearly define our hypotheses, and explain how we plan to disprove them. ${ }^{9}$

This plea is by no means original. John R. Platt, a biophysicist, beautifully laid out this argument to scientists more than 50 years ago in his wonderful essay published in Science entitled "Strong inference: Certain systematic methods of scientific thinking may produce much more rapid progress than others." ${ }^{\prime 10}$
Our field of librarianship has much in common with science. We must also clearly define our hypotheses and work towards disproving them-this is how we will advance research in librarianship.

\section{Acknowledgements}

I thank Dean and Professor Louis Pitschmann (University of Alabama Libraries) for the excellent definition of librarianship research and for providing the catalyst for this article. I also thank Professors Richard G. Finke and Travis S. Bailey (Colorado State University) for teaching me about the Scientific Method and greatly influencing my understanding of science-and of life.

\section{Notes}

1. T. C. Chamberlin, "Studies For Students: The Method of Multiple Working Hypotheses," Journal of Geology 1897, 5, 837-48.

2. J. R. Platt, "Strong Inference-Certain Systematic Methods of Scientific Thinking May Produce Much More Rapid Progress Than Others," Science 1964, 146 (364), 347-53.

3. K. R., Popper, The Logic of Scientific Discovery (Hutchinson: London, 1980).

4. R. Hoffmann, V. I. Minkin, B. K. Carpenter, "Ockham's Razor and Chemistry," Bulletin de la Société Chimique de France 1996, 133 (2), 117-130.

5. Chamberlin, "Studies For Students: The Method of Multiple Working Hypotheses."

6. R. Hoffmann, V. I. Minkin, B. K. Carpenter, "Ockham's Razor and Chemistry."

7. J. R. Platt, "Strong Inference-Certain Systematic Methods of Scientific Thinking May Produce Much More Rapid Progress Than Others."

8. W. I. B. Beveridge, The art of scientific investigation (New York, Norton [1957] [Rev. ed.]: 1957).

9. J. R. Platt, "Strong Inference-Certain Systematic Methods of Scientific Thinking May Produce Much More Rapid Progress Than Others."

10. Ibid. n 